\title{
O Serviço Social crítico no atual contexto de redemocratização da América Latina
}

\section{Critical Social Work in the current context of Latin American redemocratization}

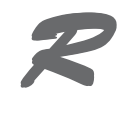

esumo

$\mathrm{O}$ artigo busca analisar as particularidades do processo de redemocratização dos regimes políticos latinoamericanos, tentando contribuir para o esclarecimento de fenômenos hoje centrais na compreensão destas sociedades e, conseqüentemente, do solo onde se desenvolvem as práticas do Serviço Social. Desde os anos 1980, a tentativa da América Latina em reorganizar sua vida pública em conformidade com os preceitos democráticos liberais demonstrou uma desigualdade de forças políticas na negociação desta transição, onde avanços políticos foram acompanhados pelo agravamento das condições de vida das maiorias nacionais. Como o Serviço Social crítico surge historicamente - no marco de ordenamentos democráticos, a conformação da profissão relaciona-se intrinsecamente com as debilidades deste processo, onde emergem novos desafios para construção da identidade dos assistentes sociais, principalmente no debate do sentido da sua prática, do processo de conhecimento crítico e no redimensionamento de propostas relevantes na defesa de um projeto socialmente necessário no contexto latinoamericano atual.

Palavras-chave: América Latina, processos políticos, democracia, Serviço Social crítico.

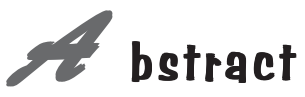

This article analyses the particularities of the redemocratization process of Latin American political regimes, in an attempt to contribute to the understanding of phenomenon central to our societies today. Since the 1980's, the attempt by Latin America to reorganize its public life in conformity with liberal democratic precepts demonstrated an inequality of political forces in the negotiation of this transition, where political advances were accompanied by the deterioration of living conditions among national majorities. Since critical Social Work historically arose in the framework of democratic regulations, the formation of the profession was intrinsically related to the weaknesses of this process, from which emerge new challenges to the construction of the identity of social workers, principally in the debate over the meaning of the practice, of the process of critical knowledge and of the redimensioning of the relevant proposals in the defense of a socially necessary project in the current Latin American context.

Key words: Latin America, political processes, democracy, critical Social Work.

\section{Douglas Ribeiro Barboza}

Assistente Social.

Mestrando em Serviço Social, Universidade do Estado do Rio de Janeiro - UERJ.

\section{Silene de Moraes Freire}

Mestre em Serviço Social pela Universidade Federal do Rio de Janeiro -UFRJ.

Doutora em Sociologia pela Universidade do Estado de São Paulo - USP.

Professora da Faculdade de Serviço Social da UERJ. 


\section{Introduçăo}

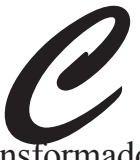
omo se sabe, o Serviço Social crítico surge, em termos históricos, no marco de ordenamentos democráticos, e a capacidade transformadora dessa prática profissional acaba por se relacionar intrinsecamente com as debilidades do incompleto e precário processo de democratização dos regimes políticos latino-americanos. Seguindo as análises de Palma (1986), a instituição da democracia -tal como concebida e impulsionada pela burguesia de formação liberal-é o "campo" onde se move o exercício das profissões, onde se define a situação e as necessidades dos grupos populares e onde se organiza e se dinamiza o movimento da classe trabalhadora. Sendo assim, o conhecimento desta democracia (suas contradições e alternativas) permite a tentativa de determinar ações possíveis e reais, superando tanto o otimismo quanto o fatalismo ingênuo, onde o Serviço Social, tal como se apresenta, pode estar mais articulado com a problemática desses processos democráticos do que se pode perceber em sua aparência. Apesar dos assistentes sociais, no exercício da sua profissão, não possuírem a capacidade de alterar qualitativamente as "regras do jogo" democráticas, "influem sobre certas realidades que condicionam as iniciativas que, contrárias ou favoráveis às mudanças, conduzem a outros níveis", e que a orientação impostas àquelas realidades poderia, indiretamente, "facilitar ou dificultar as decisões pelas mudanças" (PALMA, 1986).

Considerando essas premissas, faz-se mister compreender as peculiaridades da redemocratização da América Latina e suas influências na construção do atual cenário sociopolítico da região, por entender-se que essa compreensão é crucial para o fortalecimento da perspectiva crítica do Serviço Social latino-americano.

\section{As particularidades do "ressurgimento" das democracias na América Latina}

Ao analisarmos as discussões acerca da incompleta e precária democratização dos regimes políticos latino-americanos, podemos perceber uma propensão muito grande, dentro das ciências sociais, em debater e examinar por que certos países são democráticos e outros não. Esta ênfase em analisar se a saída de regimes autoritários afetava ou não os novos regimes que nasciam gerou uma grave tendência de se supor que a transição levaria necessariamente à instauração da democracia, mas a história - principalmente a latino-americana - provou o inverso.

Algumas pessoas diziam que o modo pela qual as ditaduras caíam exercia impacto muito grande sobre a democracia que se constituía. Anali- sava-se se haviam acabado por colapso, como na Argentina; por uma transição pelo alto, como no Brasil; e de que forma essas diferentes modalidades de transição afetariam a democracia que se erguia. Pode-se, contudo, pensar a transição como movimento, como momento provisório, não planejado. Por isso não haveria modelos comparativos daquilo que efetivamente não existe conceitualmente como fenômeno político acabado (D'ARAÚJO; CASTRO, 2000, p. 217-218).

A onda de democratização dos sistemas políticos, manifestada no Sul da Europa em meados da década de 70 e estendida posteriormente à América Latina, esteve intimamente vinculada tanto "às profundas mudanças estruturais políticas, econômicas e estratégicas desencadeadas no mundo", quanto "às pressões exercidas por poderosos atores internacionais" (governos dos Estados centrais, forças econômicas transnacionais, organizações intergovernamentais, organizações não governamentais e movimentos sociais), "em função das mais diversas motivações” (VACS, 1994 apud GÓMEZ, 2000). As novas democracias que se constituiriam se afastariam de um modelo clássico e desejado e tenderiam muito mais a uma chamada "democracia não consolidada"; democracias que permanecem sempre em estado inacabado, e que sempre são, por definição, aperfeiçoáveis (GÓMEZ, 2000, p. 93).

Para melhor entendermos esse processo, podemos distinguir duas visões claramente diferenciáveis no resgate das diversas abordagens do conceito de democracia. A primeira, assume a democracia como uma forma de relação política que permite a uma maior parte da sociedade decidir (e não só participar) sobre seu presente e futuro, tendendo a um desenvolvimento da autonomia dos personagens num processo crescente de emancipação humana. Esta, naturalmente, associada a níveis também crescentes de igualdade social, como meio e como fim do processo de democratização. A democracia implica e gera processos de transformações e rupturas com uma ordem social de profunda desigualdade, e injustiça, como é, particularmente, o caso latino-americano. Sua estabilidade como regime político e como relação social não se fundamenta na ausência de conflitos, mas sim se representa legitimamente nas diferenças e contradições sociais para processar a transformação da sociedade que aspira a maioria da população. A segunda visão de democracia é a que a entende somente como um método para administrar politicamente as relações existentes de poder para conservá-las; de um modo que a maior parte da sociedade eleja um reduzido grupo de líderes, que, com base em um acordo sobre a ordem social a conservar, tomará as decisões por essa maioria. Esta segunda concepção de democracia surge nas primeiras décadas do século XX, como um antídoto capitalista à crescente participação po- 
lítica das massas exploradas e a sua maior presença institucional através da consagração do sufrágio universal no primeiro pós-guerra.

Esta síntese conservadora de democracia de elites implica num sistema representativo e de partidos como o núcleo central do método de administração política das relações de poder, que deve funcionar como um mercado de equilíbrio entre a oferta do sistema e as demandas da sociedade. O equilíbrio se traduzirá em políticas públicas que não afetem a lógica e a capacidade crescente de acumulação. Transpondo esses pontos para uma abordagem das democracias na América Latina, é importante ressaltarmos que esta região

[...] em seus quase dois séculos de vida independente não conheceu uma única revolução burguesa que tivesse culminado na instauração de um regime democrático estável. Houve algumas revoluções burguesas, é certo: no México em 1910-1917, na Guatemala em 1844, na Bolívia em 1952, e até no Brasil a partir de 1964. Mas nenhuma delas conclui suas 'tarefas pendentes', estabelecendo um regime democrático: sua preocupação, ao contrário, foi consolidar o funcionamento do modo de produção capitalista, não introduzir a democracia burguesa. Sua meta e seu objetivo era o capitalismo, não a democracia. O molde autoritário do capitalismo latino-americano tem raizes muito profundas, que derivam de nosso passado colonial e da modalidade reacionária e dependente com a qual nossas sociedades se integraram ao capitalismo (BORÓN, 1995, p. 64).

Podemos dizer que, desde os anos 1980, apesar de a América Latina mergulhar - novamente - numa tentativa de organização da sua vida pública em acordo com os preceitos democráticos, nenhuma ditadura latino-americana, exceto a da Nicarágua, terminou por uma derrota clara, o que significou ter que negociar as condições da transição com uma evidente desigualdade de forças políticas. Depois de anos de terror do Estado, um certo "desespero" pela recuperação das liberdades individuais e públicas permitiu às forças dominantes impor suas regras de jogo político - mediante uma permanente chantagem à população sobre os riscos de um regresso autoritário caso a conflitividade e as demandas sociais se desenvolves$\mathrm{sem}^{1}$ - e empregar uma ofensiva ideológica para convencer da inevitabilidade das transições distintas e separadas no tempo: uma, em curso, para recompor o sistema representativo e os espaços de negociação política, com tempos e passos determinados com clareza; e outra, de início indeterminado, que encararia as demandas sociais que a população esperava satisfazer com a volta da de- mocracia. A teoria destas transições se fundamenta numa autonomia absoluta do político frente ao econômico; o primeiro como um campo de negociação possível, com regras precisas, mas que pode se transformar à margem do segundo, que é inegociável. Ou seja, quanto menos se afetarem as questões estruturais fundamentais, mais segura seria a transição política. Poderia se negociar os espaços de acesso ao sistema político, poderia se modificar as situações econômicas e se ampliar as participações para eleger as elites, mantendo as desigualdades sociais ${ }^{2}$.

A crença prevalecente nas ciências sociais e nas nascentes democracias era a de que havia chegado o momento de despreocupar-se das questões mais ligadas ao funcionamento de nossos capitalismos e da estrutura de classe (como a marginalidade social, a extrema pobreza, a decadência urbana e regional), pois eram problemas distantes da real preocupação dos novos tempos: eleições, partidos e regimes políticos. Sendo assim, os avanços políticos experimentados pela região nos anos 1980 foram acompanhados por um agravamento marcante das condições de vida das grandes maiorias nacionais. Este modelo de democracia acabou se tornando efetivamente num mecanismo de governabilidade, na medida em que filtra e controla as demandas sociais até níveis tolerados pelo sistema, e com isso preserva os conflitos, numa concepção de que somente com este referencial é que se pode assimilar a democracia com a governabilidade nos tempos atuais. Esses aspectos nos mostram a impossibilidade de reflexão das democracias da América Latina sobre a concepção de democracia em geral - que é inconcebível à margem de uma análise sobre a estrutura e dinâmica do capitalismo latino-americano e, mais detalhadamente, sobre a natureza dos processos de ajuste estrutural e refundação capitalista em curso na região. Ao invés de se tratar a democracia em sua abstração, o mais viável é examinar a forma, as condições e os limites da democratização em sociedades como a capitalista, que se fundam em princípios constitutivos antagônicos.

Apesar de valorizarmos a transcendência da democracia como forma de governo e como modo de vida principalmente pelas lutas latino-americanas para conquistá-la - é importante não esquecermos que, em sua concretização histórica, ela sempre se encontra interligada a uma estrutura de dominação classista, que impõe rígidos limites às suas potencialidades representativas e, em maior medida, às possibilidades de autogoverno da sociedade civil (BORÓN, 1995). Tão incorreto é considerar também que o desenvolvimento da democracia na América Latina se fecha apenas na influência dos processos de transição de cada país - pois seria o mesmo que concluir que a Argentina vive na maior das democracias possíveis, já que foi o único país onde os militares abandonaram o poder sob uma brutal derrota (Guerra das Malvinas), pois a história mais uma vez provou o inverso. 
É importante observar que o condicionamento externo é substantivo para o colapso dessas democracias, para o seu restabelecimento e para efetivação ou não da governabilidade democrática. Desta forma, poderemos desvelar como o impacto da ideologia neoliberal, que acompanha o processo de globalização, tende a afetar o desenvolvimento destas democracias, principalmente nos países periféricos.

\section{Os impactos dos "alustes neoliberais" no desenvolvimento das democracias latino- americanas}

A crise da dívida dos países latino-americanos, no início da década de 1980, gerou déficits de balança de pagamentos que tornaram inviáveis os projetos de desenvolvimento para a região, onde seus governos se dedicaram fundamentalmente a buscar saldos comerciais que pudessem diminuir esses dados (SADER, 2003). Tendo como referências fundamentais as hiperinflações embutidas nesse processo, os objetivos de desenvolvimento foram substituídos pelos de estabilidade monetária, tornando-se a mola mestra no processo de semeadura das políticas neoliberais na América Latina. A diminuição dos gastos do Estado tornou-se a principal meta dos governos que desejassem superar a inflação, tendo como algumas medidas recomendadas a privatização de empresas e a contenção nos gastos com o funcionalismo e com serviços sociais do Estado (educação, habitação, saúde e saneamento básico). Esses argumentos demonstraram, na sua fase inicial de aplicação, uma eficácia imediata, cujos efeitos foram rapidamente difundidos e reproduzidos pelos órgãos de divulgação internacionais e retomados localmente pela mídia e pelos quadros econômico-democráticos do grande capital.

O elevado custo social das estratégias "maximalistas" que orientaram a implementação das reformas econômicas neoliberais, junto com a conseqüente redução da sindicalização e do poder de barganha dos sindicatos, corroeram as bases econômicas, organizacionais e ideológicas das classes subalternas e incidiram negativamente na sua capacidade de mobilização e participação e no apoio aos partidos políticos comprometidos com políticas sociais redistributivas.

Contudo, essa vitória foi mais ideológica e cultural do que econômica. De acordo com Borón (1999), esse triunfo se assenta sobre uma derrota "epocal" das forças populares e das tendências mais profundas da reestruturação capitalista se manifestando em várias dimensões.

Desta forma, apesar da democratização ter representado um avanço político significativo na América Latina, onde países e regiões com pouca ou nenhuma tradição democrática prévia passaram a reconhecer instituições e procedimentos (sufrágio universal, eleições regulares, li- vres e competitivas, razoável garantia de liberdade de expressão e associação, etc.) que permitiram a inclusão formal de milhões de cidadãos no processo de escolha das elites políticas encarregadas das decisões coletivas, ela foi acompanhada, principalmente nas "novas democracias", por eminentes paradoxos e por relevantes problemas, que os discursos triunfais de sua implantação e consolidação não conseguem ocultar.

A segunda metade dos anos 1990 foi marcada pelo início do esgotamento deste potencial hegemônico e pelo aprofundamento da crise na região latino-americana (a mais profunda desde 1930), sendo precedidos pela crise mexicana, em 1994, e refletidos na crise argentina, na dolarização no Equador e em El Salvador. As políticas de ajuste fiscal, que pretendiam retomar o desenvolvimento econômico, a criação de empregos e os privilégios das políticas sociais, deixaram de ser solução e tornaram-se a causa da crise, desequilibrando econômica e financeiramente o continente, deixando os Estados cada vez mais enfraquecidos externa e internamente e fragmentando cada vez mais as sociedades, com altos índices de desigualdade e de exclusão. Ou seja, o funcionamento da democracia política na América Latina durante a década de 1990 não superou as próprias fragilidades inaugurais nem mesmo promoveu ou aprofundou a democracia participativa e a democracia econômico-social ${ }^{3}$. O que ocorreu realmente foi uma acentuação dos processos contrários, como baixos níveis de participação e mobilização da cidadania, ampliação da desigualdade econômico-social, instabilidade e crise de legitimidade política.

A tendência mundial de generalização da pobreza e de um alarmante aumento da desigualdade econômica e social, não só nos países da periferia do sistema capitalista, mas também entre estes e os países centrais, ficou mais perceptível na América Latina, sendo comprovada através de dados compilados por distintas agências nacionais e internacionais, que mostravam como esse fenômeno atingiu países como o Chile, onde, supostamente, o modelo neoliberal teria alcançado o seu êxito mais gritante.

Entre 1980 e 1990 a pobreza piorou como resultado da crise e das políticas de ajuste, eliminando a maior parte das conquistas alcançadas durante os anos de 1960 e 1970 na redução da pobreza. Estimativas recentes situam o número dos pobres no começo da década, dependendo da definição de pobreza, entre 130 e 196 milhões de pessoas [...]. A recessão e o ajuste dos anos oitenta também aumentaram a desigualdade de renda em grande parte da região (CEPAL, 1994, p.1).

Considerando que um dos requisitos mais relevantes da democracia é a existência de um grau bastante avançado de igualdade social - e que esta democracia não 
consegue sustentar-se sobre sociedades marcadas pela desigualdade e pela exclusão - é possível compreendermos como o processo de reconcentração de renda e de geração de pobreza, tão acentuado como o que caracteriza a reestruturação neoliberal latino-americana, acarretou numa extrema debilidade no funcionamento dos regimes democráticos na região. Gómez (2000) acredita que esta extrema debilidade dos componentes liberais, republicanos e até mesmo democráticos das "novas democracias" latino-americanas resulta, também, tanto de processos históricos complexos e de longa duração, quanto da natureza e do alcance das experiências ditatoriais ou autoritárias anteriores, sem contar a influência das principais vias percorridas pelos processos de democratização política na região nas duas últimas décadas.

Desta forma, a América Latina entra no século XXI atravessando a sua pior crise nos últimos setenta anos, marcada pela fragilidade de suas economias, pela debilidade de seus Estados e por uma grande diminuição do seu peso econômico e político no mundo. Sader (2003) considera que a crise consiste em aproximadamente duas décadas de programas de estabilização monetária, de hegemonia liberal, de predomínio da acumulação financeira, que não levaram país algum da região a recuperar o seu atraso na corrida tecnológica, a estabilizar e estender regimes democráticos e a diminuir os problemas sociais. Os impactos sociais, políticos e econômicos desta crise marcaram o futuro da região, enfraquecendo a legitimidade política e ideológica usufruída pelo neoliberalismo na última década. A incapacidade das políticas neoliberais postas em prática nas últimas duas décadas aprofundou a crise social existente, sem conseguir nem retomar o desenvolvimento nem conquistar estabilidade política, gerando uma série de crises institucionais ${ }^{4}$.

Paralelamente a este processo, a esquerda, que antes apresentava um quadro de derrota tanto pela impotência quanto pela mudança ideológica ao neoliberalismo (e que tinha como forças sobreviventes o PRD no México, o PT no Brasil e a Frente Ampla no Uruguai), passou a ganhar força com o surgimento de novas formas de resistência, principalmente após o levante zapatista de Chiapas, no México, em 1994. As vitórias eleitorais de Hugo Chávez na Venezuela e de Lúcio Gutierrez no Equador, além da alta votação de Evo Morales na Bolívia e da Frente Ampla para as Eleições de 2004 no Uruguai, revelaram a capacidade de transformação da força do movimento popular em força político-institucional neste novo período. Os triunfos eleitorais de blocos/forças que nasceram e se desenvolveram no confronto ao modelo neoliberal mostraram o crescente descontentamento social frente a este modelo, abrindo a possibilidade de uma nova tentativa de solução da esquerda (após o fracasso de 1973) para a crise hegemônica no continente, nos termos evidenciados por Sader (2003).

Porém, entre o fracasso de um modelo e sua efetiva substituição por outro pode existir um espaço de tempo muito grande e demorado, onde se exige um estado de consciência que ainda não foi verificado na maioria das sociedades capitalistas, e que requer a existência de uma proposta política que seja socialmente percebida como uma alternativa ao status quo. Como observou Borón, (1999, p.58) o grave problema que caracteriza a nossa época é que, "[...] enquanto o neoliberalismo exibe evidentes sintomas de esgotamento, o modelo de substituição ainda não aparece no horizonte das sociedades contemporâneas."

Esta debilidade da esquerda e das forças de resistências latino-americanas para enfrentar a tarefa de construção de um período pós-neoliberal, não conseguindo preencher o vazio entre o esgotamento do modelo hegemônico vigente e a capacidade de construção de alternativas ao mesmo, evidencia-se como um desafio na América Latina ${ }^{5}$.

Sendo assim, o surgimento de novas forças sociais e políticas, bem como o fortalecimento de forças construídas anteriormente, tornam o atual contexto um momento histórico particular em que os projetos tanto de continuidade como de ruptura com o neoliberalismo se evidenciam de forma mais concreta. As particularidades entre o desempenho eleitoral da esquerda e a perda de influência sobre diferentes setores populares podem abrir um processo de debate interno sobre suas concepções políticas, mostrando que apesar da resistência e dissidência não estarem mortas falta-lhes ainda uma articulação sistemática e intransigente, para que não acabem colocando em risco toda a acumulação de forças geradas nas últimas décadas na oposição a este modelo.

\section{A nova caracterização da estrutura do Estado e das relações Estado-sociedade}

É certo que a debilidade congênita da democracia política nos países latino-americanos assumiu novos traços em de- 
corrência das reformas econômicas neoliberais implementadas nas últimas décadas pelos governos democraticamente eleitos, e que estas reformas, analisadas sob o ângulo da correlação de forças entre capital e trabalho, implicaram em um incremento notável do poder econômico, social e político dos setores e grupos mais transnacionalizados do capital que são beneficiários diretos de processos de concentração e centralização. Para Gómez (2000), a estrutura do Estado e as relações Estado-sociedade têm se configurado numa direção contrária ao desenvolvimento mais completo da democracia política e ao avanço de uma maior democracia participativa e econômico-social, onde as reformas neoliberais debilitam exponencialmente as capacidades das instituições estatais em termos de ação e coordenação geral das políticas públicas, minando a ação do Estado enquanto agente de desenvolvimento e integração social, de valorização e eficácia dos serviços públicos e do funcionalismo público, desmontando assim as bases da constituição dos atores sociais e da representação simbólica coletiva da comunidade política.

Com a profunda reestruturação econômica e social e com o apogeu dos ideais neoliberais, assistiu-se a uma expansão da mercantilização da vida social que resultou num perceptível desequilíbrio na relação entre mercado, Estado e sociedade, onde a opressora presença dos mercados e sua hegemonia em setores crescentes da vida pública contemporânea trouxe à tona a discutível relação de incompatibilidade entre essa hegemonia e a preservação da democracia (BORÓN, 1999).

Um dos pontos principais dessa incompatibilidade consiste no fato de que a lógica expansiva dos direitos de cidadania própria de um modelo democrático se contrapõe ao movimento inverso que se origina nos mercados. Seguindo as análises de Borón (1999, p. 36-40), a relativa capacidade dos sindicatos, dos partidos e das organizações representativas de camadas populares em traduzir a sua presença política em benefícios sociais concretos para os trabalhadores foram a base para a progressiva conquista de direitos sociais e econômicos durante a história dos capitalismos democráticos no século XX, cujo resultado foi um crescente processo de "socialização de demandas" pelo qual um grande número de exigências e necessidades antes consideradas "privadas" (educação, saúde, seguridade social, etc.) tornaram-se bens coletivos, e sua provisão dependeu de uma extrema redefinição do papel exercido pelos Estados nacionais. Porém, na fase constituída a partir da contra-ofensiva burguesa - a partir da década de 1970, verifica-se um processo oposto de "privatização" ou "mercantilização" dos velhos direitos de cidadania, onde os direitos, as demandas e as necessidades, anteriormente consideradas como assuntos públicos, transformaram-se em questões individuais diante das quais os governos de inspiração neoliberal julgam que seu único papel consiste em "criar condições favoráveis para que seja o mercado o encarregado a lhes dar uma resposta".
Soares (1998), ao elucidar as causas e conseqüências da redução considerável do gasto social e a respectiva deterioração dos serviços sociais públicos e dos subsídios ao consumo popular básico, aponta que a adoção de uma política social de cunho neoliberal provoca e acentua a estratificação social, cujos elementos básicos são as desigualdades - nas condições e na qualidade de trabalho, no consumo e na proteção social. Ainda, segundo autor, na realidade latino-americana, apesar de não haver uma total ausência de políticas públicas sociais, houve um verdadeiro desmantelamento - em nome da "necessidade de reformas" de programas sociais, muitos dos quais em pleno funcionamento e com coberturas razoáveis.

Ao tentarmos esclarecer os postulados neoliberais na área social, podemos sintetizá-los, basicamente, no pertencimento do bem-estar social ao âmbito privado (suas fontes "naturais" são a família, a comunidade e os serviços privados), onde o Estado só passa a intervir quando surge a necessidade de aliviar a pobreza absoluta e de produzir aqueles serviços que o setor privado não pode ou não quer fazer. Surge a proposta da substituição de um Estado de BemEstar Social por um Estado de Beneficência Pública ou Assistencialista, onde o ideário neoliberal abole tanto os direitos sociais e a obrigação da sociedade de garanti-los por meio da ação estatal, como também a universalidade, a igualdade e a gratuidade dos serviços sociais. As estratégias para essa redução da ação estatal configuram-se em: corte do gasto social (eliminação de programas e redução de benefícios); focalização do gasto (canalização para os chamados grupos indigentes, que devem "comprovar" a sua pobreza); privatização da produção de serviços e descentralização dos serviços públicos no nível local.

Gómez (2000) analisa que essas reformas acabaram por materializar a ruptura do padrão histórico "estadocêntrico" de relação entre Estado e sociedade na América Latina (responsável por profundas desigualdades, discriminações e formas de dominação), que vigorou durante décadas sob o signo da inclusão social, em nome do desenvolvimento e da Nação, bem como da incorporação ao mercado, à cultura e a uma certa idéia de cidadania política e social. Dessa forma, o Estado tornou-se mais incapaz de estabelecer e garantir determinadas condições mínimas de exercício efetivo da cidadania democrática consagrada normativamente. Paralelo a este processo, e como conseqüência das mudanças operadas na correlação de forças entre as classes sociais, a pretensa autonomia desse Estado se desenvolveu sob signos contrários: ao mesmo tempo em que desaparece em face dos setores e grupos mais transnacionalizados e financeirizados do capital, transforma-se em ostensiva independência com relação às classes subalternas ${ }^{6}$.

Refletidas essas questões, segue necessária a apreensão quanto aos novos desafios que o atual estágio do processo de desenvolvimento capitalista - que tem reforçado 
a fragmentação social, ampliando a diferenciação de classes e as desigualdades sociais e modificando radicalmente o mercado de trabalho - traz para os assistentes sociais.

\section{A conformação da perspectiva crítica do Serviço Social na contemporaneidade}

O projeto neoliberal e o processo de reestruturação produtiva nos marcos da mundialização do capital vêm implicando numa radicalização da questão social, na redução das responsabilidades públicas governamentais ante as necessidades da maioria da população e na potencialização da estratégia de privatização da coisa pública (privatizações da saúde, da educação, e das políticas públicas); cenário esse comum na realidade latino-americana atual e que exerce influência condicionante na ação profissional. O desmonte do Estado nas suas funções sociais, nas suas respostas à questão social, implica profundas mudanças nos processos de trabalho, nas formas organizativas das classes trabalhadoras, nos movimentos sociais. Durante a construção da pesquisa o "Serviço Social na América Latina Contemporânea" ", pudemos perceber que, estando a profissão inserida num projeto hegemônico do capital - o Estado de Bem-Estar Social ou suas versões precárias e tardias latino-americanas, as mudanças societárias, a mudança de projeto e de estratégia do capital afetam diretamente a mesma, gerando diferentes respostas que perpassam tanto o enfrentamento às políticas neoliberais quanto a aceitação complacente das mesmas, em muitos casos vinculados às condições laborais dos trabalhadores ${ }^{8}$.

Por ser uma profissão que lida com as manifestações da questão social, essas mudanças societárias têm transformado as características dessas manifestações. Não a questão social, a sua centralidade, pois a contradição capital-trabalho continua presente; mas os seus desdobramentos. As suas manifestações têm mudado as características, a sua abrangência é maior, e a sua heterogeneidade. Então, nesse sentido, muda também o que alguns autores chamam da matéria da intervenção profissional.

Eu diria que essas transformações vêm influenciando o Serviço Social na medida que elas vêm fazendo uma contra-reforma do Estado latinoamericano, reduzindo os direitos sociais, reduzindo a qualidade da prestação dos serviços sociais. E como o assistente social é um profissional que trabalha a partir da questão social, com os direitos sociais e os meios de acessá-los, viabilizando à população meios de acesso e de exercício dos seus direitos, à medida em que esses direitos são desmontados isso afeta diretamente a ação profissional (IAMAMOTO, 2001, p.3).
Acrescenta-se outros pontos importantes neste contexto, como a influência dessas transformações na formação acadêmica (onde a relação estreita com o mercado de trabalho e a idéia da formação técnico-instrumental é muito forte atualmente em várias Escolas da América Latina) e na relação salarial. Emerge a idéia de os assistentes sociais serem possuidores de uma prática liberal, que possam fazer parte de escritórios, vendendo serviços privados, via ONG ou outras formas de terceirização do emprego. Há também de se destacar a leitura muito fragmentada da realidade, perdendo-se a visão de totalidade, com o ressurgimento de propostas de busca da especificidade dentro de uma perspectiva endógena da profissão, incluído o caráter liberal-corporativista ${ }^{9}$.

Nesse cenário, o Serviço Social brasileiro tem uma posição muito explícita, que vem sendo consolidada no denominado projeto ético-político, na defesa da responsabilidade do Estado no âmbito das políticas universais, dos parâmetros da Constituição de 1988 - que representa um tipo de resposta à questão social muito distinta da prática governamental, aplicada a partir da década de $90^{10}$. Uma posição de defesa das políticas sociais, da assistência, da saúde pública, do Sistema Único de Saúde (SUS), da Lei Orgânica da Assistência Social (LOAS), dos benefícios derivados e previstos nos direitos constitucionais, na preocupação com a descentralização relacionada às decisões e recursos.

Ampliando as reflexões para o exemplo argentino, é impossível analisar essa questão sem pensar o papel da ditadura, não só na fragmentação da sociedade, mas também no esvaziamento do potencial crítico acadêmico (com o fechamento de muitas universidades, interrupções de carreiras, muitos exilados), a perda de praticamente uma geração inteira, o que deixou marcas muito graves na sociedade argentina. Destaca-se, também, a questão do grande avanço da direita dentro das universidades (o que também implicou numa regressão em termos de conteúdo), somada à incapacidade - por razões societárias e da própria categoria - de se fazer esse "ajuste de contas" com o legado da Reconceituação ${ }^{11}$.

Dessa forma, aprofunda-se o ecletismo na profissão, a superposição de teorias sociais incompatíveis (em termos de concepções teórico-metodológicas), tem-se um arranjo de técnicas e teorias muito pouco rigorosas. Não existe um processo unificado de debate em torno do currículo, sendo este diferente em cada unidade acadêmica, não existindo um processo de síntese - como tem a categoria brasileira sobre o código de ética, sobre o currículo ${ }^{12}$.

Analisados todos esses aspectos, torna-se indubitável o emergir - nesse cenário de intensos processos de mudanças - de alguns desafios que influem diretamente, e incondicionalmente, à conformação de uma identidade crítica do Serviço Social na América Latina.

A fragmentação imposta pelas derrotas políticas dos anos 60 e 70 impediu a continuação do intento à articula- 
ção e ao aprofundamento do vínculo latino-americano no Serviço Social. Esse novo atual contexto, de maior visibilidade das urgências sociais e de expansão de lutas sociais diversas na região, possibilita uma retomada deste pensamento, onde o conhecimento - por parte da categoria das particularidades da realidade dos países da América Latina é situação primordial para o avanço da condição de mero discurso.

O fortalecimento da dimensão teórico-metodológica e da dimensão ético-política, que permitam reposicionar a profissão com fortes competências e permitam superar a mera instrumentalização das políticas sociais é um outro desafio exposto à categoria. A questão da transformação do Estado, do desmonte dos direitos e das políticas sociais, incide diretamente sobre o espaço socioocupacional da profissão. Isto implica para os assistentes sociais em uma necessidade de se reconhecer como um profissional na atuação das políticas sociais, na luta por uma maior democratização e pela garantia dos direitos sociais conquistados (as políticas sociais universais, constitutivas dos direitos de cidadania como dever do Estado, políticas organizadas a partir do financiamento compulsório da sociedade e não apenas da ação voluntária, a luta pelo modelo de seguridade social inscrito na Constituição de 1988). Sequer estamos falando na ampliação de direitos, e sim da mera defesa de direitos conquistados, o que é um desafio que não admite a menor demora nem a menor concessão, na medida das possibilidades.

Isto recorre à problemática da conciliação da teoria à prática, da defasagem entre as bases de fundamentação teórica da profissão e o trabalho de campo. A transição da bagagem teórica acumulada ao enraizamento da profissão na realidade se correlaciona - não unicamente, mas de forma relevante- à necessidade de conhecimento das diversas tendências teórico-metodológicas e à capacidade de se aprofundar e defender alguma delas para uma possível superação do ecletismo existente na formação acadêmica. Com a clara ofensiva neoconservadora do pensamento único hegemônico, durante a década de 90 e o início do século XXI, a disputa - não só no Serviço Social, mas em toda a sociedade - entre as tendências conservadoras e as tendências progressistas adota um novo perfil onde o pensamento conservador (que ainda não se constitui como hegemônico na profissão) assume um caráter renovado, forte. Ele vem encoberto, não se manifestando como conservador, mas, ao contrário, incorporando e apropriando-se de discursos progressistas (a sociedade civil, a participação, a parceria, a harmonia, o combate à miséria, o combate à fome, a descentralização), renovando e recolocando nesses discursos o seu conteúdo conservador. Nesse cenário se conforma o desafio da profissão, o de explicitar os pressupostos inseridos nas diversas tendências e defini-los claramente com esse esquema conservador progressista ou com toda a heterogeneidade que isso possa ter, mantendo vivo o pensamento progressista e o pensamento crítico $^{13}$.

No refletir de todas essas questões, fica clara a importância de compreender o atual momento como de necessidade de intercâmbio, de tentativa de articulação das forças sociais progressistas em busca de uma alternativa ao projeto neoliberal. Reconhecendo que essa luta, além de ser uma luta nacional, é, acima de tudo, uma luta latinoamericana, pois as questões com a qual se defrontam os diferentes países da região ultrapassam o ângulo da questão particular nacional, e acabam por adotar uma certa universalidade que precisa ser reconhecida.

\section{Considerações finais}

A crise atual na América Latina está cada vez mais marcada pelas tendências políticas e econômicas derivadas de uma inserção comum no mercado mundial, que induzem à homogeneização básica desses processos no continente. Porém, as decisões políticas - mediante as quais se assumem e se enfrentam as contradições engendradas a partir desta estrutura de produção comum - determinam variantes e processos nacionais que exigem uma maior compreensão das similitudes e diferenças de cada país ao se propor um exercício de análise. Percebe-se, também, que esse novo estágio do processo de desenvolvimento capitalista tem influenciado a conformação do Serviço Social na região. Conforme observou Netto (1996), ninguém pode duvidar que o período histórico em que estamos situados é marcado por transformações societárias que afetam diretamente o conjunto da vida social e incidem fortemente sobre as profissões, suas áreas de intervenção, seus suportes de conhecimento e de implementação, suas funcionalidades, etc. São as conjunturas, de rápidas e intensas transformações societárias, que constituem o lócus privilegiado para o processamento de alterações profissionais. $\mathrm{O}$ desafio consiste em determinar as mediações que conectam as profissões àquelas transformações.

Assim sendo, é fundamental fornecer uma contribuição para a compreensão dos processos políticos da América Latina, partindo do reconhecimento de que nossa região nunca esteve tão povoada por regimes políticos democráticos conforme os cânones liberais - como na contemporaneidade. Entretanto, é nesse cenário que observamos nitidamente em toda a região os custos sociais que as reformas estruturais de cunho neoliberal promoveram.

Desse modo, faz-se mister evidenciar a importância do Serviço Social analisar esse cenário como elemento crucial para a compreensão das demandas que hoje circunscrevem a profissão na América Latina. Apesar de já ter quatro décadas, o Movimento de Reconceituação até hoje traz alguns desafios para a prática profissional. Tais desafios partem do reconhecimento de que é preciso fa- 
zer avançar o processo de luta pelos direitos e democratização da política, da cultura e da economia.

Enraizar um projeto defendido pelos assistentes sociais, sustentado nesses compromissos, não depende apenas do profissional, mas da evolução política das sociedades onde se inserem. Na América Latina, o assistente social precisa lutar na contramão do projeto neoliberal. Assim, é de suma importância reconhecer as debilidades do atual cenário latino-americano, onde emergem novos desafios para construção da identidade dos assistentes sociais, principalmente no debate do sentido da sua prática, do processo de conhecimento crítico e no redimensionamento de propostas relevantes na defesa de um projeto socialmente necessário para as sociedades latino-americanas.

\section{Recebido em 02.05.2006. Aprovado em 19.06.2006.}

\section{Referênciass}

BORGIANNI, E.; GUERRA, Y.; MONTAÑO, C. (Orgs.). Servicio Social crítico. Hacia la construcción del nuevo proyecto éticopolítico profesional. São Paulo: Cortez, 2003.

BORÓN, A. Asociedade civil depois do dilúvio neoliberal. In: SADER, E.; GENTILI, P.(Orgs.). Pós-neoliberalismo: as políticas sociais e o Estado democrático. Rio de Janeiro: Paz e Terra, 1995, p. 63-118.

. Os novos leviatãs e a polis democrática: neoliberalismo, decomposição estatal e decadência da democracia na América Latina. In: SADER, E.; GENTILI, P. (Orgs.). Pósneoliberalismo II: que Estado para que democracia? Rio de Janeiro: Vozes, 1999, p. 7-67.

CEPAL. Panorama social de América Latina. Santiago: CEPAL, 1994.

D’ARAÚJO, M.C.; CASTRO, C. Democracia e Forças Armadas no Cone Sul. Rio de Janeiro: Editora FGV, 2000.

DULCICH, R. Conflito social e respostas do Estado na Argentina contemporânea: algumas notas. In: VIII ENCONTRO NACIONAL DE PESQUISADORES EM SERVIÇO SOCIAL ABEPSS/UFJF, 2002. Anais... Juiz de Fora, 2002. 1 CD-ROM.

FREIRE, S. de M. As armadilhas da recente notoriedade da sociedade civil no Brasil. In: FREIRE, L. M.B.; FREIRE, S. de M.; CASTRO, A. M. B.(Orgs.). Serviço Social, política social e trabalho. São Paulo: Cortez, 2006.

GÓMEZ, J. M. Política e democracia em tempos de globalização. Rio de Janeiro: Vozes; Buenos Aires: CLACSO; Rio de Janeiro: LPP, 2000.

GUERRA, Y. Novas perspectivas de atuação profissional: o perfil do profissional hoje. Revista Construindo o Serviço Social. Instituto de Pesquisas e Estudos da Divisão do Serviço Social, Instituição Toledo de Ensino, Bauru, 2002.

IAMAMOTO, M. V. O Serviço Social na América Latina. Boletim Proealc, Centro de Ciências Sociais-UERJ, Rio de Janeiro, n. 8, set./out. 2001, p. 3-4. Entrevista.
. O Serviço Social na América Latina. Boletim Proealc, Centro de Ciências Sociais -UERJ, Rio de Janeiro, n. 9 , nov./ dez., 2001, p. 3-4. Entrevista.

MARRO, K. Apuntes para pensar la formación y el ejercicio professional del Trabajo Social argentino. In: SEMINÁRIO LATINO-AMERICANO DE SERVIÇO SOCIAL - Articulação Latino-Americana e Formação Profissional e Oficina Nacional da ABEPSS, 2003, Porto Alegre. Anais... Porto alegre, 2003. 1 CD ROM.

NETTO, J. P. Transformações societárias e Serviço Social. Notas para uma análise prospectiva da profíssão no Brasil. Revista Serviço Social \& Sociedade, São Paulo: Cortez, n. 50, p. 87-132, abril 1996.

PALMA, D. A prática política dos profissionais: o caso do Serviço Social. Tradução José Paulo Netto. São Paulo: Cortez, 1986.

RETANA JIMÉNEZ, J. As dimensões da ética e da política no Serviço Social: a particularidade da Costa Rica. 2002. Dissertação (Mestrado em Serviço Social) - Escola de Serviço Social, Universidade Federal do Rio de Janeiro, Rio de Janeiro, 2002.

SADER, E. A vingança da história. São Paulo: Boitempo, 2003.

SOARES, L. T. R. Ajuste neoliberal e desajuste social na América Latina. Rio de Janeiro: UFRJ, 1998.

\section{Notas}

1 Segundo Borón (1995, p. 64-65), esse processo teve como produto a adesão de um importante segmento da esquerda latino-americana a uma concepção ingenuamente otimista e "facilista" da democracia, que se concentra em dois supostos: a) o caráter supostamente linear e irreversível dos progressos democráticos; b) a crença, teoricamente errônea e historicamente falsa, de que a democracia é um projeto que se esgota apenas na "normalização" das instituições políticas.

2 A autonomia do "político transformável" frente ao "econômico inegociável" - onde o direito à alternância de partidos e nos governos se garantiria sempre quando não significasse a alternância de projetos econômico-sociais era considerada condição única e essencial para manter a salvo a democracia

3 Segue-se a distinção, nos critérios de definição e na inter-relação dessas três dimensões de democracia, encontrada em Gómez (2000), onde o autor, com base no desenvolvimento histórico das "antigas" democracias parte do pressuposto de que a democracia formal ou política não é apenas uma possibilidade, mas também uma condição necessária para incorporar e alcançar as dimensões participativa e econômico-social.

4 Enquanto que nos seus anos de apogeu todos os governos que se dispunham a assumir os preceitos neoliberais conseguiam se eleger e se reeleger, como aconteceu nos casos argentino (Carlos Menem) e brasileiro (Fernando Henrique Cardoso), no cenário atual a situação se inverteu, pois com o seu "esgotamento", aqueles que assumiam e mantinham este modelo perderam rapidamente a sua 
legitimidade ou se esgotaram. São os casos de Fernando de la Rúa, na Argentina, de Vicente Fox, no México, e de Sanchez de Losada, na Bolívia (SADER, 2003).

5 O caso de Hugo Chávez é um exemplo, pois mesmo apoiado pelo descontentamento popular com as alternativas das elites, não conseguiu ainda constituir um projeto alternativo para compor o novo bloco de poder.

6 Leva-se em consideração que essa tentativa de recuperação da noção de sociedade civil também é adotada - com bastante empenho - pelos ideais neoliberais, onde se desloca o originário sentido antiditatorial desta noção para uma concepção de redução da sociedade civil a mero braço "terceirizado" do Estado e do mercado, responsável pela prestação de serviços e pela consecução despolitizada do interesse geral, ao mesmo tempo em que é negada como espaço por excelência de práticas e lutas hegemônicas (FREIRE, 2006).

7 A pesquisa vem sendo desenvolvida desde 2004 no Programa de Estudos de América Latina e Caribe (Proealc), do Centro de Ciências Sociais da Universidade do Estado do Rio de Janeiro (UERJ). Neste artigo mencionamos algumas reflexões de diversas entrevistas realizadas com assistentes sociais latino-americanos, que abordam preocupações com a temática aqui focalizada.

8 Neste contexto, a profissão acaba enfrentando um movimento onde, por um lado, surgem tendências que re-atualizam o conservadorismo, ocasionando um novo irracionalismo via intervenções cada vez mais microscópicas e pontuais; por outro, há a formação de uma massa crítica que tem se nutrido da bibliografia brasileira e vem avançando na sua análise ontológica do cotidiano (GUERRA, 2002).

9 Destaca-se, também, uma forte tendência a "terapeutizar" o projeto profissional, via influência norte-americana do social work sistêmico, que mantém em Palo Alto, Califórnia, um centro de formação de pós-graduação muito conhecido entre os seguidores da corrente sistêmica na América Latina (RETANA JIMÉNEZ, 2002).

10 Ao contrário do projeto da Carta de 88 (de um atendimento que respeite o controle social da população ao nível das políticas públicas, as políticas públicas universais, o pacto federativo, a descentralização como descentralização de decisões de recursos), o que se percebe a partir da década de 1990 é a identificação do atendimento às necessidades da população quase a partir da questão orçamentária. Um livro caixa de entrada e saída de dinheiro que no fundo invertem as decisões: ao invés do orçamento respeitar a constituição, o que se tem é uma inversão e uma subversão (IAMAMOTO, 2001).

11 A esse respeito ver Marro (2003) e Dulcich (2002).

12 Soma-se a isto toda a tendência de retorno ao passado, com bibliografia obsoleta, sem produção, caracterizando o contexto argentino, uruguaio, e de alguns outros países da região, com uma substantiva diferença do contexto brasileiro, que já possuía uma pós-graduação, novos textos, novos pesquisadores. Na década de 90, a Argentina (através de um convênio entre a Universidad de la Plata e a PUC de São
Paulo), e o Uruguai (através de um convênio entre a Universidad de la República e a UFRJ), levam o mestrado para essas universidades, produzindo um intercâmbio que permitiu dar um salto de qualidade no debate teórico do Serviço Social. Assim passou a incorporar, no debate uruguaio e argentino, o debate crítico do Brasil, em relação: à análise crítica das políticas sociais, à percepção da função social da profissão na sociedade capitalista, às transformações societárias, ao neoliberalismo, à reforma do Estado, à reestruturação produtiva, à centralidade do trabalho nas relações sociais, etc. Em relação, também, às obras clássicas como a de Marilda Iamamoto e de José Paulo Netto, entre outros.

13 Pensamento crítico este já visto como obsoleto, onde a categoria exploração é substituída pela categoria ou pelo conceito de exclusão social, a contradição capital versus trabalho passa a ser substituída pela parceria, os direitos sociais garantidos no Estado passam a ser transformados como liberdade de mercado, os direitos do trabalhador são cada vez mais sucateados e passam a ser substituídos pelo direito do consumidor - como se algo viesse para ocupar o lugar, e um pouco a justificar. A esse respeito recomenda-se Borgianni, Guerra e Montaño (2003).

\section{Douglas Ribeiro Barboza}

douglasbarboza@yahoo.com.br

\section{Silene de Moraes Freire}

silene-freire@ig.com.br

Universidade do Estado do Rio de Janeiro

Faculdade de Serviço Social

Rua São Francisco Xavier, 524, $8^{\circ}$ andar, B1. E, Sala 8018 Maracanã - Rio de Janeiro/RJ

CEP: 20550-013 